\title{
Neonatal Diabetes Mellitus: A Tale Still to Resolve
}

\author{
Alok Raghavi*, Jamal Ahmad ${ }^{2}$, Ashok Kumar Kaul' ${ }^{1}$, Prerna Singh ${ }^{1}$, Himanshu Mamtani ${ }^{1}$, Syed Muntazir \\ Andrabi ${ }^{1}$, Aman Nikhil ${ }^{1}$, Saba Noor ${ }^{2}$ and Brijesh Kumar Mishra ${ }^{3}$ \\ ${ }^{1}$ Department of Biological Sciences and Bioengineering, Indian Institute of Technology, India \\ ${ }^{2}$ Rajiv Gandhi Centre for Diabetes \& Endocrinology, JN Medical College, Aligarh Muslim University Aligarh, India \\ ${ }^{3}$ Department of Endocrinology and Metabolism, GTB Hospital, University of Delhi, India
}

Submission: October 10, 2017; Published: November 10, 2017

*Corresponding author: Alok Raghav, Department of Biological Sciences and Bioengineering, Indian Institute of Technology, Kanpur, India, Email: alokalig@gmail.com

\begin{abstract}
Transient diabetes mellitus and permanent diabetes mellitus in neonates are the primary forms of neonatal diabetes mellitus. TNDM shows symptoms of diabetes mellitus initially in the first week of birth and undergo remission in a few months. In PNDM, insulin secretion is affected worsely and therefore require exogenous insulin from sources. The subject of PNDM is susceptible for intrauterine growth retardation (IUGR). Among the genetic makeover, mutations in Kir6.2 and SUR1 subunit contribute mostly in the development of this form. The management successfully includes the application of insulin shots subcutaneously to infants to avoid the hypoglycaemia episodes.
\end{abstract}

\section{Introduction}

Neonatal diabetes mellitus (NDM) is a rarest devastating metabolic disorder of newborns. It is characterized by significant high blood glucose in combination with low insulin levels. On the basis of clinical recognition the NDM is further classified into two prime groups namely, transient NDM (TNDM) and permanent NDM (PNDM), which differ from each other on the basis of duration of insulin dependence. The transient form of NDM, which is of generic origin, is a developmental disorder of insulin secretion from pancreatic beta cells that resolves postnatally mostly, but persist in around $50 \%$ to $60 \%$ neonatal cases. There are no recognized grounds that can predict a neonate with diabetes will have permanent or transient form. Recently some molecular mechanisms are evolved that plays role in the understanding of PNDM and TNDM.

\section{Clinical characteristics}

The symptoms of neonatal diabetes mellitus presents as hyperglycemia, in rare cases episodes of dehydration and ketoacidosis which may lead to coma within the first month of life. Inadequate insulin production with significant less level of blood is primarily occurs in neonatal diabetes mellitus. Insulin therapy from exogenous source is the hope in its management.

\section{Clinical attributes of TNDM}

TNDM is a disorder of insulin generation from pancreatic beta cells that resolves postnatally. It is presents in $50 \%$ to $60 \%$ cases of diabetes in neonates characterized by intrauterine growth retardation (IUGR) [1]. High episodes of IUGR sets the crucial role of insulin in fetal development especially during the last trimester of pregnancy. TNDM is characterized by insufficient insulin production and needs exogenous insulin supply. Investigations comes negative for anti-islet antibodies and also for HLA class II haplotypes conferring type 1 diabetes mellitus susceptibility [2]. Study has quoted defect in cell integrity in TNDM presentation [3]. Literature has also reported in exocrine pancreatic insufficiency in TNDM subjects [4]. Furthermore, the cellular domain behind the TNDM pathogenesis id still unclear. Most patients suffering from TNDM recovered from episodes within a year, leaving few with constant persistent glucose intolerance. In a French cohort study, the results showed that five out of seven TNDM presenting patients who were older than 8 years of age respond to permanent hyperglycemia requiring insulin therapy [5]. Moreover results of another cohort study on TNDM subjects revealed that, diabetes mellitus (DM) episodes recurred in 11 subjects out of 18 patients older than 4 years of age [6]. Conclusively, the "transient form" of the disease 
is associated with permanent failure of $ß$-cells with variable expression phases during the growth and development. Puberty is the prime factor that plays role in recurrent diabetes mellitus, which is severely associated with insulin resistance.

\section{Clinical attributes of PNDM}

It is the less common form of diabetes compared to TNDM occurring in neonate. This form of diabetes occurs in neonatal period and does not undergo remission. In this form of diabetes there are no exactly precise clinical presentations that can predict, whether a neonate with symptoms of diabetes without any dysmorphic features will occasionally develop permanent or transient form of disease. It is reported that cases with the PNDM do not represents always IUGR, that is the characteristic feature of TNDM 6q phenotype [5,6].

\section{Diagnosis of neonatal diabetes mellitus}

Diagnosis of NDM occur within the first days or months of birth with hyperglycemia presentation. Rarely there are associated neural complications. The presentation time in NDM is variable, and there is diagnostic problem in differentiation between monogenic and autoimmune type 1 diabetes in the early-onset children. In a previous study conducted on 111 diabetic children who desire insulin within first year of life, it is reported a highest frequency of protective HLA antigens and less frequent in children with diabetes onset before $180 \mathrm{~d}$ compared to those with more than $180 \mathrm{~d}$ [7]. Another studies reported that incidences of diabetic cases prior to 6 months of age are monogenic in origin $[8,9]$. The data presently available strongly favours that episodes of diabetes diagnosed prior to 6 months of age are probably monogenic in origin and thus required genetic screening. Hyperglycemia is commonly attributed by fasting plasma glucose $7.0 \mathrm{mmol} / \mathrm{L}$ [10]. While NDM plays important role in the differential diagnosis of neonatal hyperglycemia, it is also quite rarely occurring complications of neonates. High infusion rates of glucose doesn't effect the neonatal hyperglycemia in preterm and also in low-weight birth neonates, as prematurity and IUGR, both are concomitantly associated with immaturity of B-cells and also its mass respectively that results in insulin deficiency [11,12]. Other factors that cause complications includes inotropes, glucocorticoids management, lipid infusions, caffeine and theophylline [13]. Another important fact is that some surgical procedures, anaesthesia along with critical illness also causes elevation in blood sugar levels, potentially secondary to stress episodes and concomitant elevated expression of cortisol and epinephrine, less insulin release and disturbed glucose utilization [13]. NDM is also associated with secondary hyperglycemia caused due to amino acid metabolism [13]. Interestingly making differentiation between monogenic and autoimmune diabetes mellitus can be a potential diagnostic dilemma that imparts variable duration of presentation of NDM.

\section{Molecular makeover of TNDM and PNDM}

TNDM is commonly sporadic in nature, but in some cases paternal transmission has been reported in patients having non- diabetic fathers [14]. Study also reported that few patients had partial duplication of long arm of the paternal chromosome 6 [15]. Origin of TNDM occurs only, if the possibility of chromosome duplication arises from father. Paternal transfer of chromosomal abnormalities leads to hyperglycemia and susceptibility of diabetes in later stages of life.

There are associated factors for the cause of PNDM molecular mechanisms, primarily include mutation in KCNJ11 gene encoding the protein Kir6.2 subunit of the potassium ATPase complex, that involve in regulation of potassium ion across the membrane [16]. Dominant mutations occurring in ABCC8 also accounts for PNDM episodes [17].

\section{Management and treatment of NDM}

The potassium channels plays important role in cellular response to metabolic changes in insulin secretion. Approach of switching insulin injections to oral glibenclamide drug therapy proves to be promising approach in the treatment and is also safe [18]. Insulin therapy is excellent choice therapy in management of NDM with appreciable weight gain and growth in neonates. In few circumstances, glucose and calorie intake deprivation has been instituted in neonates in the form of hyperglycemia to restrict insulin therapy approach. In neonates with presentation of TNDM, subcutaneous ultralente insulin approach is appreciable without the episodes of hypoglycaemia [19].

\section{Long-term risk for health of children with NDM}

Infants with NDM, have permanent diabetes, others have remission of the former, that later recurre, leaving some patients with permanent remission. Moreover, diabetes mellitus may recur after a long duration, one should may consider its remission permanent, and also consider the neonatal diabetes as a prediabetic state [20]. It is question always with the NDM that do the long-term outcomes in neonates indicate that NDM is to be consider more than one disorder? NDM have few similarities with insulin-dependent diabetes as it happens in older children. In this heredity plays a prime role along with HLA haplotypes [20]. It is concluded from the previous study that permanent and long-term remissions of diabetes are very unusual in insulindependent diabetes mellitus, that is quite frequent in NDM [20].

\section{Conclusion}

Neonatal diabetes mellitus is a rare conditions presented in neonates in two forms mainly TNDM and PNDM. However, it is probably a matter of concern to understand the molecular and genetic mechanism lies behind this worst complications. The understanding of NDM and its forms easily help in the proper management in neonates.

\section{References}

1. Von Muhlendahl KE, Herkenhoff H (1995) Long-term course of neonatal diabetes. N Engl J Med 333(11): 704-708.

2. Shield JP, Gardner RJ, Wadsworth EJ, Whiteford ML, James RS, et al. 
(1997) Aetiopathology and genetic basis of neonatal diabetes. Arch Dis Child Fetal Neonatal Ed 76(1): F39-F42.

3. Ferguson AW, Milner RD (1970) Transient neonatal diabetes mellitus in sibs. Arch Dis Child 45(239): 80-83.

4. Fosel S (1995) Transient and permanent neonatal diabetes. Eur J Pediatr 154(12): 944-948.

5. Metz C, Cave H, Bertrand AM, Deffert C, Giroux BG, et al. (2002) Neonatal diabetes mellitus: chromosomal analysis in transient and permanent cases. The Journal of Pediatrics 141(4): 483-489.

6. Temple IK, Gardner RJ, Mackay DJ, Barber JC, Robinson DO, et al. (2000) Transient neonatal diabetes: widening the understanding of the etiopathogenesis of diabetes. Diabetes 49(8): 1359-1366.

7. Iafusco D, Stazi MA, Cotichini R, Cotellessa M, Martinucci ME, et al. (2002) Permanent diabetes mellitus in the first year of life. Diabetologia 45(6): $798-804$.

8. Flanagan SE, Edghill EL, Gloyn AL, Ellard S, Hattersley AT (2006) Mutations in KCNJ11, which encodes Kir6.2, are a common cause of diabetes diagnosed in the first 6 months of life, with the phenotype determined by genotype. Diabetologia 49(6): 1190-1197.

9. Flanagan SE, Patch AM, Mackay DJ, Edghill EL, Gloyn AL, et al. (2007) Mutations in ATP-sensitive $\mathrm{K}$ channel genes cause transient neonatal diabetes and permanent diabetes in childhood or adulthood. Diabetes 56(7): 1930-1937.

10. Standard of Medical Care in Diabetes (2017) American Diabetes Association (ADA) guidelines 40(Suppl 1): 1-142.

11. Meetze W, Bowsher R, Compton J, Moorehead H (1998) Hyperglycemia in extremely- low-birth-weight infants. Biol Neonate 74(3): 214-221.
12. Ogilvy Stuart AL, Beardsall K (2010) Management of hyperglycaemia in the preterm infant. Arch Dis Child Fetal Neonatal Ed 95(2): F126-F131.

13. Beardsall K, Vanhaesebrouck S, Ogilvy Stuart AL, Vanhole C, Palmer CR, et al. (2010) Prevalence and determinants of hyperglycemia in very low birth weight infants: cohort analyses of the NIRTURE study. J Pediatr 157(5): 715-719.

14. Von Muhlendahl KE, Herkenhoff $\mathrm{H}$ (1995) Long-term course of neonatal diabetes. N Engl J Med 333(11): 704-708.

15. Cave H, Polak M, Drunat S, Denamur E, Czernichow P (2000) Refinement of the 6q chromosomal region implicated in transient neonatal diabetes. Diabetes 49(1): 108-113.

16. Gloyn AL, Pearson ER, Antcliff JF, Proks P, Bruining GJ, et al. (2004) Activating mutations in the gene encoding the ATP-sensitive potassium-channel subunit Kir6.2 and permanent neonatal diabetes. N Engl J Med 350(18): 1838-1849.

17. Babenko AP, Polak M, Cave H, Busiah K, Czernichow P, et al. (2006) Activating mutations in the ABCC8 gene in neonatal diabetes mellitus. N Engl J Med 355(5): 456-466.

18. Pearson ER, Flechtner I, Njolstad PR, Malecki MT, Flanagan SE, et al. (2006) Switching from insulin to oral sulfonylureas in patients with diabetes due to Kir6.2 mutations. N Engl J Med 355(5): 467-477.

19. Mitamura R, Kimura H, Murakami Y, Nagaya K, Makita Y, et al. (1996) Ultralente insulin treatment of transient neonatal diabetes mellitus. The Journal of Pediatrics 128(2): 268-270.

20. Von Mühlendah KE, Herkenhoff H (1995) Long-term course of neonatal diabetes. N Engl J Med 333(11): 704-708.

\begin{tabular}{l} 
Your next submission with Juniper Publishers \\
will reach you the below assets \\
- Quality Editorial service \\
- Swift Peer Review \\
- Reprints availability \\
- E-prints Service \\
- Manuscript Podcast for convenient understanding \\
- Global attainment for your research \\
- Manuscript accessibility in different formats \\
( Pdf, E-pub, Full Text, Audio) \\
- Unceasing customer service \\
Track the below URL for one-step submission \\
https://juniperpublishers.com/online-submission.php \\
\hline
\end{tabular}

